\title{
Mite, cat, and cockroach exposure, allergen sensitisation, and asthma in children: a case-control study of three schools
}

Richard Sporik, Susan P Squillace, Jim Mark Ingram, Gary Rakes, Richard W Honsinger, Thomas A E Platts-Mills

\begin{abstract}
Background-The amount of allergen necessary to sensitise genetically "at risk" children is unclear. The relation between allergen exposure and asthma is also uncertain.

Methods-To ensure a wide range of allergen exposures the data from case-control studies of asthma in children aged 12-14 years attending three schools in Los Alamos, New Mexico and Central Virginia were combined. Skin prick tests to indoor and outdoor allergens and bronchial hyperreactivity to histamine were assessed in children with and without symptoms of asthma. The concentration of mite, cat, and cockroach allergens in dust from the children's homes was used as a marker of exposure.
\end{abstract}

Results-Three hundred and thirty two children (157 with asthmatic symptoms and 175 controls) were investigated. One hundred and eighty three were classified as atopic on the basis of allergen skin prick tests and 68 as asthmatic (symptoms plus bronchial responsiveness). The prevalence and degree of sensitisation to mite and cockroach, but not cat, was strongly associated in atopic children with increasing domestic concentrations of these allergens. Asthma was strongly associated with sensitisation to indoor allergens $\left(p<10^{-6}\right)$ and weakly to outdoor allergens $(p=$ $0.026)$. There was an association between current asthma and the concentration of mite allergen amongst atopic children $(p=0.008)$ but not amongst those who were specifically mite sensitised $(p=0.16)$.

Conclusions-The domestic reservoir concentration of mite and cockroach, but not cat, allergen was closely related to the prevalence of sensitisation in atopic children. However, the prevalence of current asthma had a limited relationship to these allergen measurements, suggesting that other factors play a major part in determining which allergic individuals develop asthma.

(Thorax 1999;54:675-680)

Keywords: asthma; children; allergen exposure; atopy

A consistent feature of asthma in children and young adults is increased levels of IgE specific to indoor allergens. Evidence comes from cross sectional studies of children ${ }^{1-4}$ and young adults,${ }^{5}$ studies from children and young adults presenting to the emergency department with asthma exacerbations, ${ }^{6-8}$ and from an "at risk" population studied prospectively. ${ }^{9}$ In addition, raised levels of total IgE are also seen. ${ }^{10}{ }^{11}$ Both genetic and environmental factors are considered to contribute to this relationship. ${ }^{12-15}$ The amount of domestic allergen exposure necessary for sensitisation to occur and the amount necessary to result in symptoms in sensitised children is, however, not clearly defined although provisional values have been suggested. ${ }^{16}{ }^{17} \mathrm{~A}$ number of studies have also suggested that allergen avoidance can reduce the prevalence of sensitisation and may subsequently reduce the prevalence of asthma. ${ }^{18} 19$

Allergen exposure can be measured by the reservoir concentration of allergens from a number of domestic sites. While this is only a surrogate marker of what is inhaled, it has the advantage of being a summary measurement of recent exposure. The concentration of mite allergen in an infant's environment has been shown to be a predictor of future mite sensitisation. ${ }^{919}$ Peat et al have shown that, across different climatic regions in Australia, the concentration of dust mite allergen, expressed as a community average, was a good index of the prevalence of mite sensitisation. ${ }^{20}$ To fully explore the exposure-response relationship it is necessary to recruit sufficient individuals living in areas of high and low exposure which rarely occur in one community. ${ }^{17} 2122$ We have therefore pooled data from cross sectional studies of three middle schools located in different environments ${ }^{23-25}$ and assessed the effect of allergen exposure, both at the domestic and community level, on the occurrence of sensitisation to mite, cat, and cockroach allergens. In addition, we analysed whether the occurrence of asthma was related to current allergen exposure.

\section{Methods}

PATIENTS

Children attending three schools were studied: Buford Middle School, Charlottesville, Virginia; Henley Middle School, Albermarle County, Virginia; and Los Alamos Middle School, Los Alamos, New Mexico. The schools were selected because of their diverse geographical and socioeconomic settings, being located in city, rural, and high altitude communities, respectively. All children between 12 and 14 years of age were eligible for
20 April 1999

Accepted for publication

26 April 1999 
enrolment. Ethical permission for these studies was obtained from the Human Investigation Committee of the University of Virginia, the Los Alamos Medical Center, and the local School Boards.

DESIGN OF STUDY

The study consisted of two parts, a screening phase followed by the detailed investigation of a selected sample. The same protocols ${ }^{23}{ }^{25}$ were used at each school. In phase I of the study a respiratory questionnaire was administered as part of a general science class. A total of 1621 questionnaires were completed (Buford 608, Henley 446, and Los Alamos 567, representing $95 \%, 94 \%$, and $95 \%$ of the school populations, respectively). On the basis of responses to the questionnaire the children were divided into those with symptoms of asthma and those without (controls). All those with symptoms of asthma and an equal number of randomly chosen control children were invited to participate in the second phase of the study. Three hundred and thirty two (including 175 controls) underwent skin prick testing and their bronchial responsiveness to histamine was assessed. Skin reactivity to extracts of the house dust mites (Dermatophagoides farinae and $D$ pteronyssinus), cockroach, cat dander, and pollens (grass mix, ragweed mix, and a tree mix) (Miles, Spokane, WA) were assessed using a lancet technique. A positive reaction was recorded if the mean diameter of the skin weal was $\geqslant 4 \mathrm{~mm}$ larger than the negative control, and children were considered strongly sensitised if the skin weal was $\geqslant 8 \mathrm{~mm}$. A DeVilbiss hand held nebuliser was used to assess bronchial responsiveness to inhaled histamine in the children according to the technique of Yan et al. ${ }^{27}$ Children were considered hyperresponsive if at or before the maximal cumulative dose of $3.9 \mu \mathrm{mol}$ histamine the forced expiratory volume in one second $\left(\mathrm{FEV}_{1}\right)$ decreased by $20 \%$ of the post saline value. The dose response slope (percentage change in the final $\mathrm{FEV}_{1}$ from the post saline baseline divided by the total cumulative dose of histamine given) was also calculated. ${ }^{20} 28$ Children were considered to have asthma if they reported wheezing in the previous year and showed bronchial responsiveness to $3.9 \mu \mathrm{mol}$ or less of histamine.

Dust was collected by a standard procedure from the mattress, bedroom floor, living room floor and kitchen floor of 127 Buford houses, 68 Henley houses, and 108 Los Alamos houses between September 1992 and September $1993 .^{30}$ The dust was sieved and weighed and, after aqueous extraction, the content of $\operatorname{Der} p 1$, $\operatorname{Der} f$ 1, Fel d 1, and Bla $g 2$ allergens (derived from the house dust mites $D$ pteronyssinus and $D$ farinae, cat, and the German cockroach Blatella germanica, respectively) were measured using two site monoclonal antibody enzyme linked immunoassays. ${ }^{31}{ }^{32}$ In keeping with the recommendations of an international workshop, the results were expressed as micrograms of allergen per gram of sieved dust $(\mu \mathrm{g} / \mathrm{g}) .{ }^{16}$ The limit of detection for group 1 mite allergens $(\operatorname{Der} p 1$ $+\operatorname{Derf} 1$ ) was $0.2 \mu \mathrm{g} / \mathrm{g}$, for Fel d 1 was $0.5 \mu \mathrm{g} / \mathrm{g}$, and for Bla g 2 was $0.08 \mu \mathrm{g} / \mathrm{g}$ (2 units/g).
STATISTICAL ANALYSIS

Parametric and non-parametric analyses were performed. Results were expressed as geometric means and $95 \%$ confidence intervals. All p values were two tailed. As allergen concentrations were not normally distributed, results were $\log _{10}$ transformed for analysis. To examine the degree of sensitisation with increasing allergen exposure without making assumptions about threshold levels for sensitisation, the highest domestic exposure to mite and cat allergen in atopic children was ranked and used to divide these atopic children into six groups; the first group contained the majority of children with undetectable allergen and consisted of 29 children, followed by five equal groups of 27 children. The association of allergen concentration and the prevalence of sensitisation and asthma was tested using the $\chi^{2}$ test for trend based on the $\log _{10}$ median allergen concentration in each group. Regression correlations between the $\log _{10}$ (dose response slope + 3) and $\log _{10}$ group 1 mite allergen concentration were also calculated (Stata, College Station, Texas, USA).

\section{Results}

DOMESTIC ALLERGEN CONCENTRATION

There was a wide range in the concentration of mite, cat, and cockroach allergens in the 303 homes studied (fig 1). Extremely low concentrations of mite allergen were seen in Los Alamos and high concentrations in the Henley School District. Cockroach allergen (Bla g 2) was much less common and was only consistently found in the homes of children attending Buford school. Cat allergen was detectable in most of the houses, although in lower concentrations in Buford.

ALLERGEN EXPOSURE AND SENSITISATION One hundred and eighty three children were classified as atopic and 149 non-atopic on the basis of their skin test results. Dust samples were collected from the homes of 164 atopic

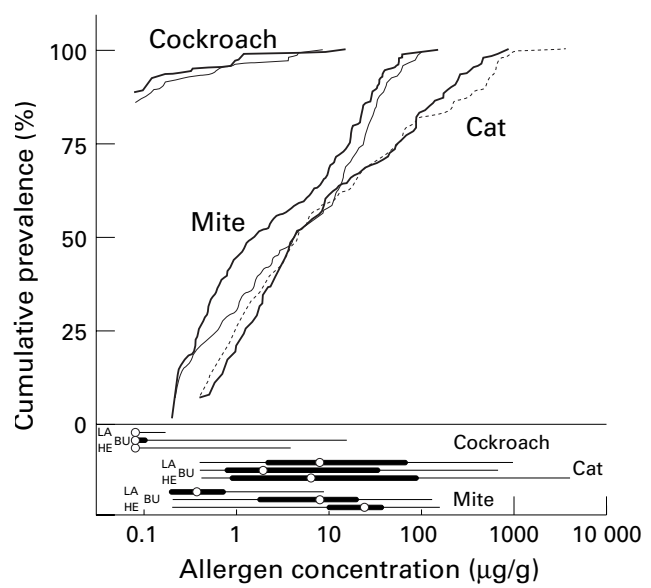

Figure 1 Cumulative prevalence of highest domestic cockroach, mite, and cat allergens (all schools combined). The bold lines represent the highest concentration found in the homes of atopic children while the remaining lines represent those found in the homes of non-atopic children. The lower panel shows the median ( $\circ$, range, and 25-75th centiles for cockroach, mite, and cat allergen in Los Alamos $(\mathrm{L} A)$, Buford $(B U)$ and Henley ( $H E)$. 
Table 1 Occurrence of sensitisation and asthma with increasing domestic allergen exposure

\begin{tabular}{|c|c|c|c|c|c|c|}
\hline \multicolumn{2}{|c|}{$\begin{array}{l}\text { Highest domestic allergen concentration } \\
(\mu g / g)\end{array}$} & \multicolumn{2}{|c|}{$\begin{array}{l}\text { Percentage of atopic children sensitised } \\
\text { specifically to each allergen }\end{array}$} & \multicolumn{3}{|c|}{ Percentage of children with asthma } \\
\hline Group $^{*}$ & Median (range) & Sensitised $^{\star \star}$ & $\begin{array}{l}\text { Strongly } \\
\text { sensitised }\end{array}$ & Atopic & $\begin{array}{l}\text { Specifically } \\
\text { sensitised }\end{array}$ & Non-atopic \\
\hline \multicolumn{7}{|l|}{ Mite } \\
\hline 1 & $0.2(<0.2-0.3)$ & $38(11 / 29)$ & $17(5 / 29)$ & $24(7 / 29)$ & $36(4 / 11)$ & $9(2 / 23)$ \\
\hline 2 & $0.42(0.3-0.6)$ & $41(11 / 27)$ & $11(3 / 27)$ & $19(5 / 27)$ & $27(3 / 11)$ & $8(1 / 13)$ \\
\hline 3 & $0.92(0.62-1.8)$ & $33(9 / 27)$ & $15(4 / 27)$ & $22(6 / 27)$ & $33(3 / 9)$ & $10(2 / 21)$ \\
\hline 4 & $5.0(1.8-10.0)$ & $63(17 / 27)$ & $26(7 / 27)$ & $26(7 / 27)$ & $29(5 / 17)$ & $11(3 / 27)$ \\
\hline 5 & $17.1(10.2-23.9)$ & $70(19 / 27)$ & $33(9 / 27)$ & $30(8 / 27)$ & $37(7 / 19)$ & $14(3 / 22)$ \\
\hline 6 & $38.2(24.0-155)$ & $\begin{array}{l}78(21 / 27) \\
\mathrm{p}=0.00003\end{array}$ & $\begin{array}{l}52(14 / 27) \\
p=0.0003\end{array}$ & $\begin{array}{l}56(15 / 27) \\
p=0.0084\end{array}$ & $\begin{array}{l}57(12 / 21) \\
p=0.165\end{array}$ & $\begin{array}{l}3(1 / 33) \\
p=0.68\end{array}$ \\
\hline \multicolumn{7}{|l|}{ Cat } \\
\hline 1 & $0.6(<0.5-0.9)$ & $28(8 / 29)$ & $7(2 / 29)$ & $37(11 / 29)$ & $62(5 / 8)$ & $18(6 / 33)$ \\
\hline 2 & $1.5(0.9-1.9)$ & $26(7 / 27)$ & $0(0 / 27)$ & $22(6 / 27)$ & $43(3 / 7)$ & $11(2 / 18)$ \\
\hline 3 & $3.2(2.0-4.4)$ & $48(13 / 27)$ & $7(2 / 27)$ & $22(6 / 27)$ & $23(3 / 13)$ & $0(0 / 17)$ \\
\hline 4 & $9.3(4.5-23.0)$ & $37(10 / 27)$ & $11(3 / 27)$ & $33(9 / 27)$ & $50(5 / 10)$ & $12(3 / 26)$ \\
\hline 5 & $64(23.4-112)$ & $15(4 / 27)$ & $7(2 / 27)$ & $33(9 / 27)$ & $100(4 / 4)$ & $0(0 / 20)$ \\
\hline 6 & $270(123-920)$ & $\begin{array}{l}26(7 / 27) \\
p=0.302\end{array}$ & $\begin{array}{l}7(2 / 27) \\
p=0.564\end{array}$ & $\begin{array}{l}26(7 / 27) \\
p=0.853\end{array}$ & $\begin{array}{l}29(2 / 7) \\
\mathrm{p}=0.980\end{array}$ & $\begin{array}{l}4(1 / 25) \\
\mathrm{p}=0.042^{\#}\end{array}$ \\
\hline \multicolumn{7}{|c|}{ Cockroach } \\
\hline 1 & $<0.08(<0.08)$ & $20(29 / 145)$ & $3(4 / 145)$ & $29(41 / 145)$ & $34(10 / 29)$ & $6(7 / 119)$ \\
\hline \multirow[t]{2}{*}{2} & $0.33(>0.08-15.6)$ & $72(13 / 18)$ & $28(5 / 18)$ & $39(7 / 18)$ & $38(5 / 13)$ & $25(5 / 20)$ \\
\hline & & $\mathrm{p}=0.00014$ & $\mathrm{p}=0.0009$ & $\mathrm{p}=0.51$ & $\mathrm{p}=1.0$ & $\mathrm{p}=0.015$ \\
\hline
\end{tabular}

‡The highest domestic concentration of mite and cat allergen among atopic children was ranked and used to divide the population into six groups.

$\star \star$ Allergen weal diameter $\geqslant 4 \mathrm{~mm}$.

$\star \star \star$ Allergen weal diameter $\geqslant 8 \mathrm{~mm}$, this being a subgroup of those senstised.

$\mathrm{p}=\mathrm{chi}$ square test for trend (groups scored by $\log _{10}$ median allergen concentration) for mite and cat; Fisher's exact test or chi-square, where appropriate, for cockroach.

"Inverse relationship.

and 139 non-atopic children. There was no difference in the concentration of allergens found in the homes of atopic and non-atopic children (mite, $\mathrm{p}=0.3$; cat, $\mathrm{p}=0.5$; cockroach, $\mathrm{p}=0.1)$. Figure 1 shows the cumulative frequency distributions of each allergen by atopic status.

The prevalence of allergen specific sensitisation in atopic children was associated with the child's highest domestic concentration of mite $(\mathrm{p}<0.0001)$ and cockroach allergen $(\mathrm{p}=$ $0.0001)$, but not with cat allergen $(p=0.3$; table 1). No lower threshold for sensitisation was seen. The degree of sensitisation, as measured by the size of the skin prick response, was also associated with increasing concentrations of mite and cockroach allergen (table 1). Cockroach allergen appeared to be particularly effective at sensitising, with all atopic children exposed to more than $0.32 \mu \mathrm{g} / \mathrm{g}$ being sensitised. The prevalence of sensitisation to each of

Table 2 Mean community allergen concentration (geometric mean, 95\% confidence interval), and the occurrence of allergen sensitisation

\begin{tabular}{|c|c|c|c|}
\hline \multirow[b]{2}{*}{ Allergen } & \multicolumn{3}{|l|}{ Schools } \\
\hline & Los Alamos $(n=108)$ & Buford $(n=127)$ & Henley $(n=68)$ \\
\hline \multicolumn{4}{|l|}{ Mite } \\
\hline Mite ( $\mu$ g group $1 / \mathrm{g}$ ) & $0.5(0.4$ to 0.6$)$ & $5.9(4.5$ to 7.7$)$ & $16.6(11.7$ to 23.4$)$ \\
\hline $\begin{array}{l}>2 \mu \mathrm{g} / \mathrm{g}^{\star} \\
\text { Mite sensitised }\end{array}$ & $5(5 \%)$ & $93(73 \%)$ & $62(91 \%)$ \\
\hline (\% atopic children) & $24(29 \%)$ & $41(72 \%)$ & $29(69 \%)$ \\
\hline \multicolumn{4}{|l|}{ Cat } \\
\hline Cat $(\mu \mathrm{g} \mathrm{Fel} d 1 / \mathrm{g})$ & 13.7 (9.2 to 20.4$)$ & 6.9 (4.6 to 10.3$)$ & 10.5 (5.4 to 20.3$)$ \\
\hline$>8 \mu \mathrm{g} / \mathrm{g}^{\star}$ & $56(52 \%)$ & $42(33 \%)$ & $33(48 \%)$ \\
\hline $\begin{array}{l}\text { Cat sensitised }{ }^{\star \star} \\
\quad(\% \text { atopic children) }\end{array}$ & $34(40 \%)$ & $8(14 \%)$ & $13(31 \%)$ \\
\hline \multicolumn{4}{|l|}{ Cockroach } \\
\hline Cockroach ( $\mu \mathrm{g}$ Bla g 2/g) & $0.04(0.04$ to 0.044$)$ & $0.13(0.11$ to 0.16$)$ & $0.08(0.07$ to 0.09$)$ \\
\hline$>0.08 \mu \mathrm{g} / \mathrm{g}(2 \mathrm{U} / \mathrm{g})^{\star}$ & $4(4 \%)$ & $32(25 \%)$ & $2(3 \%)$ \\
\hline $\begin{array}{l}\text { Cockroach sensitised } \star \star \\
(\% \text { atopic children })\end{array}$ & $22(26 \%)$ & $19(33 \%)$ & $6(14 \%)$ \\
\hline
\end{tabular}

${ }^{\star}$ Number of houses with allergen level greater than previously proposed "threshold" value. ${ }^{16}$ $\star \star N u m b e r$ of specifically sensitised children among the children tested in each school, (expressed as a $\%$ of atopic children in each school). the three indoor allergens (including cat) in atopic children was also positively associated with the mean community concentration of each allergen (table 2). In those 136 children sensitised to indoor allergens, sensitisation to house dust mite was the most prevalent $(71 \%)$, followed by cat $(40 \%)$ and cockroach $(35 \%)$. Multiple sensitisation was not uncommon; $65 \%$ of sensitised children were solely sensitised to one indoor allergen, $26 \%$ to two, and $10 \%$ to all three. The commonest pattern of sensitisation was isolated sensitisation to mite $(35 \%)$ followed by isolated sensitisation to cat $(15 \%)$.

\section{ASTHMA AND ALLERGEN EXPOSURE}

Sixty eight children were identified who had symptoms and bronchial hyperreactivity (i.e. asthma) and this represented $4.2 \%$ of all the children screened. The number of control children, those with symptoms alone, and those with asthma were 53,51 and 17, respectively, in Los Alamos, 80, 24 and 31 in Buford, and 38, 18 and 20, respectively, in Henley. An equal number of boys and girls had asthma. Fifty six $(82 \%)$ of the children with asthma were atopic compared with $38 \%$ of the control children $\left(\mathrm{p}<10^{-6}\right)$ and $67 \%$ of those with symptoms $(\mathrm{p}=$ 0.03 ). Atopy was more common in boys ( $\mathrm{p}=$ 0.06 ). Sensitisation to indoor allergens was also associated with the presence of symptoms and strongly associated with asthma in each school. ${ }^{23}{ }^{25}$ Sensitisation to outdoor allergens was weakly associated with asthma $(\mathrm{p}=0.026)$ but showed no consistent pattern, with the highest prevalence of sensitisation seen in control children from Los Alamos.

The effect of increasing domestic allergen exposure on symptoms and symptomatic bronchial hyperresponsiveness was analysed using the same exposure groups as those in table 1. The proportion of children with asthma was not significantly related to mite, 
Table 3 Numbers of children with symptoms and symptomatic bronchial hyperresponsiveness (BHR) by increasing exposure to domestic allergens

\begin{tabular}{|c|c|c|c|c|}
\hline Allergen & $\mu g / g$ median (range) & Symptoms and BHR & Symptoms & Control \\
\hline \multicolumn{5}{|l|}{ Mite* } \\
\hline 1 & $0.2(<0.2-0.3)$ & 9 & 18 & 25 \\
\hline 2 & $0.42(0.3-0.6)$ & 6 & 16 & 18 \\
\hline 3 & $0.92(0.62-1.8)$ & 8 & 20 & 20 \\
\hline 4 & $5.0(1.8-10.0)$ & 10 & 16 & 28 \\
\hline 5 & $17.1(10.2-23.9)$ & 11 & 4 & 34 \\
\hline 6 & $38.2(24.0-155)$ & 16 & 13 & 31 \\
\hline \multicolumn{5}{|l|}{$\mathrm{Cat}^{\#}$} \\
\hline 1 & $0.6(<0.5-0.9)$ & 17 & 12 & 33 \\
\hline 2 & $1.5(0.9-1.9)$ & 8 & 14 & 23 \\
\hline 3 & $3.2(2.0-4.4)$ & 6 & 16 & 22 \\
\hline 4 & $9.3(4.5-23.0)$ & 12 & 14 & 27 \\
\hline 5 & $64(23.4-112)$ & 9 & 11 & 27 \\
\hline 6 & $270(123-920)$ & 8 & 20 & 24 \\
\hline \multicolumn{5}{|c|}{ Cockroach ${ }^{\star \star}$} \\
\hline 1 & $<0.08(<0.08)$ & 48 & 82 & 134 \\
\hline 2 & $0.33(>0.08-15.6)$ & 12 & 5 & 21 \\
\hline
\end{tabular}

*Asthma vs controls, $\mathrm{p}<0.55$; asthma vs symptoms, $\mathrm{p}=0.006$ (positive).

${ }^{\#}$ Asthma vs controls, $\mathrm{p}<0.43$; asthma vs symptoms, $\mathrm{p}=0.12$ (negative).

${ }^{\star \star}$ Asthma vs controls, $\mathrm{p}=0.33$; asthma vs symptoms, $\mathrm{p}=0.016$.

$\mathrm{p}$ values analysed by $\chi^{2}$ test for trend for mite and cat exposure groups (see table 1 ) and $\chi^{2}$ for cockroach.

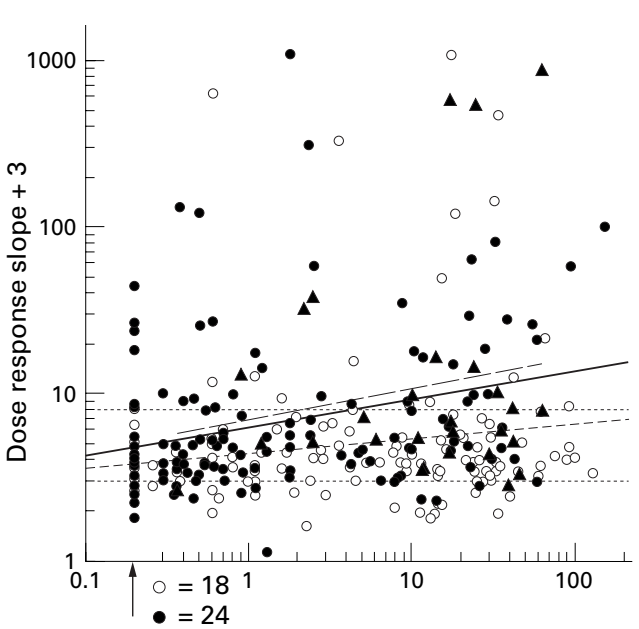

Highest domestic Gp1 allergen concentration

Figure 2 Level of airway responsiveness to histamine (dose response slope +3 ) plotted against the highest domestic concentration of house dust mite allergen in atopic (filled symbols, solid line), non-atopic (open symbols, dotted lines), and the subgroup of atopic children solely mite sensitive (filled triangles, long dash) with their respective regression lines. The horizontal reference lines correspond to a dose response slope of 3 which represents no change during bronchial provocation, and 8.1 which represents a $P D_{20}$ at 3.9 umol of histamine. among the symptomatic children increased with increasing mite allergen concentration $(p<0.006)$. By contrast, the proportion of children with bronchial hyperresponsiveness among the symptomatic children decreased, though not significantly, with increasing exposure to cat allergen $(p=0.15)$.

The proportion of atopic children with asthma symptoms and bronchial hyperresponsiveness increased with increasing concentrations of house dust mite allergen $(p=0.008$; table 1). By contrast, no effect of mite allergen was seen in non-atopic children. There was no significant effect of cat exposure on asthma either for atopic ( $p=0.85)$ or specifically allergic children $(p=0.98)$. The proportion of nonatopic children with asthma was low overall, but was slightly lower in children with higher exposure to cat allergen ( $p=0.042$; table 1$)$. The effect of mite allergen exposure on atopic children was reflected by the increasing bronchial responsiveness to histamine (doseresponse slope) with higher house dust mite allergen concentrations in atopic children $(r=$ 0.26 , $\mathrm{p}<0.001$; fig 2). However, there was a wide scatter of results and a significant trend was also seen in non-atopic children $(r=0.19$, $\mathrm{p}=0.027)$. The regression lines crossed the dose-response slope value corresponding to a $\mathrm{PD}_{20}$ of $3.9 \mu \mathrm{mol}$ at a mite allergen concentration of $4 \mu \mathrm{g} / \mathrm{g}$ for atopic children and $600 \mu \mathrm{g} / \mathrm{g}$ (extrapolated) for non-atopic children. In those atopic children sensitive to mite there was no significant association between the proportion with asthma and current exposure $(p=0.16)$, nor in the dose-response slope (mite sensitive, $r$ $=0.19, \mathrm{p}=0.07$; solely mite sensitive, $\mathrm{n}=29, r$ $=0.17, \mathrm{p}=0.37 ;$ mite non-sensitive, $r=0.20, \mathrm{p}$ $=0.09)$. Similarly, in those sensitised to cat no association with domestic exposure was seen ( $p$ $=0.98$ ). There was also no relationship for those sensitised to cockroach and their domestic exposure $(\mathrm{p}=1.0)$, although the number of sensitised children was small (table 1).

\section{Discussion}

In this multicentre case-control study of middle school children we found that the current domestic concentration of allergen was a major determinant of sensitisation to house dust mite and cockroach. However, this relationship between current exposure and sensitisation was not apparent for cat allergen. We have previously shown that asthma, whether defined as symptoms or as symptomatic bronchial hyperresponsiveness, is strongly associated with sensitisation to indoor allergens. ${ }^{23}{ }^{25}$ What is important in the present analysis is that, although the relevant allergens were different in the three schools, the relationship between sensitisation and asthma was consistent. By contrast, when sensitised children were considered there was no strong relationship between asthma and the highest domestic allergen concentration.

An explanation for these differences in the exposure-sensitisation relationships could be that mite and cockroach allergens are only found in sufficient concentrations in the home, while cat allergen is also found in appreciable concentrations outside the home. ${ }^{33-35}$ Cat allergen should be considered not only a domestic but also a community allergen. We have previously shown in a prospective study that exposure to house dust mite during infancy is more strongly associated with sensitisation at the age of 11 years than exposure at age $11 .{ }^{9}$ It was therefore surprising that a single spot measurement of current exposure in the present study shows such an association, although the strength of association was lower (odds ratio $\sim 3$ compared with 16). It is possible that current measurements of allergen in dust are both an index of exposure and also surrogate markers of more permanent features such as living at altitude or living in poverty. 
By pooling data from three populations it was possible to explore the effects of a wide range of mite and cat allergen exposures. We have previously estimated the prevalence of current asthma in each of the schools studied. ${ }^{23}{ }^{25}$ In two of the schools (Buford and Henley) asthma was strongly associated with mite sensitisation but was independent of current mite exposure. Los Alamos is an area with very low concentrations of house dust mite, a correspondingly low prevalence of mite sensitisation, where asthma is not associated with mite sensitisation. When data from Los Alamos were included in the analysis the results remained unchanged. In particular, asthma in mite sensitive children was not significantly associated with current mite exposure. However, for atopic children increasing exposure to mite allergen was strongly related to an increased prevalence of asthma. The lack of a major effect of current allergen exposure on the prevalence of asthma once sensitisation has occurred is an important observation. ${ }^{36}$ There are a number of possible explanations: (1) once sensitisation has occurred asthma is independent of allergen exposure; (2) there has been a misclassification of sensitisation; (3) there has been a misclassification of exposure; and (4) there are unmeasured confounders. Explanation (1) appears unlikely, given that symptoms can be exacerbated with exposure to inhaled allergen and asthma improves with total avoidance. ${ }^{15}$ (2) Allergen skin prick test with standardised extracts is a very sensitive way to detect allergen specific IgE. However, given the complex nature of many allergens an additional non-IgE mediated mechanism could explain the modest, but significant, effect of increasing allergen concentration amongst non-atopic children. (3) The highest reservoir concentration of allergen may not be a sensitive marker of the day to day changes that determine personal exposure. Indeed, the correlation between airborne or settling allergen, presumably a more direct measurement of allergen exposure, and reservoir measurements is not close. ${ }^{37}$ (4) There may be factors which protect sensitised individuals from asthma. ${ }^{20}$ Conversely, there are multiple other factors such as virus infection, endotoxin exposure, and air pollution that can contribute to the severity of symptoms in allergic individuals. ${ }^{36}$ These would all tend to interfere with the quantitative correlation between current exposure and symptoms.

There are a number of limitations to this study. While three large general populations of children were screened, skin testing and bronchial challenges were performed on a limited number of children, selected either for the presence or absence of respiratory symptoms. Thus the children studied include the population of interest and an equally sized, randomly chosen, control group, but not the entire population, which may have resulted in a selection bias. In addition, to obtain the wide range of exposures necessary to fully explore the exposure-response relationship it was necessary to study different populations. By pooling the data from three populations we have assumed that atopic children are a homogeneous group that behave similarly in diverse environments. Given that most of those not exposed to mite allergen lived in Los Alamos, and most of those exposed to cockroach lived in Buford, it is impossible to exclude "ecological" or other local factors confounding the results.

In summary, this study of children from three population based case-control studies confirms that the prevalence of sensitisation to mite and cockroach allergen is related to the degree of current allergen exposure. Asthma was also related to the degree of mite allergen exposure in atopic children, though not among those who were already sensitised to mite. The hypothesis that the prevalence of sensitisation and asthma could be reduced by allergen avoidance regimes in infancy and early childhood is being actively investigated by a number of groups. In keeping with recent results from Scandinavia, the concentration of cat allergen in the children's houses was not significantly related to either specific sensitisation or asthma. ${ }^{17}{ }^{38}$ Reservoir measurements of mite allergen provide summary markers of cumulative exposure as indicated by the significant association between this marker and sensitisation. ${ }^{9} 1920$ The results reported here may be due in part to the inadequacies of exposure assessment but are more likely to reflect the many confounders that influence the development of symptoms in allergic individuals. $^{36} 39$

The authors wish to thank the staff and students of Los Alamos, Buford, and Henley Middle Schools; Ross Melton for help in questionnaire preparation; Gail Rose, Weyman Price, Susan Merriam, Marlene Muller, Debbie Claytor, Jim H Sussman, Judith Woodfolk, Gates Hoover, Robert Call for technical assistance in the schools; and James Platts-Mills for data retrieval. The study was supported by grants AI-20565, and U19-AI-34607 from the National Institutes of Health, and GCRC Grant RR-00847.

1 Sears MR, Herbison GP, Holdaway MD, et al. The relative risks of sensitivity to grass pollen, house dust mite and cat risks of sensitivity to grass pollen, house dust mite and cat
dander in the development of childhood asthma. Clin Exp Allergy 1989;19:419-24

2 Rosenstreich DL, Eggleston P, Kattan M, et al. The role of cockroach allergy and exposure to cockroach allergen in causing morbidity among inner-city children with asthma. N Engl F Med 1997:336:1356-63.

3 Call RS, Smith TF, Morris E, et al. Risk factors for asthma in inner city children. F Pediatr 1992;121:862-6.

4 Duff AL, Pomeranz ES, Gelber LE, et al. Risk factors for acute wheezing in infants and children: viruses, passive smoke, and $\operatorname{IgE}$ antibodies to inhalant allergens. Pediatrics 1993;92:535-40

5 Cookson WOCM, DeKlerk NH, Ryan GR, et al. Relative risks of bronchial hyper-responsiveness associated with skin-prick test responses to common antigens in young adults. Clin Exp Allergy 1991;21:472-9.

6 Sporik R, Platts-Mills TAE, Cogswell JJ. The exposure and sensitisation to house dust mite of children admitted to sensitisation to house dust mite of children admitted
hospital with asthma. Clin Exp Allergy 1993;23:740-6.

7 Gelber LE, Seltzer LH, Bouzoukis JK, et al. Sensitization Gelber LE, Seltzer LH, Bouzoukis JK, et al. Sensitization
and exposure to indoor allergens as risk factors for asthma among patients presenting to hospital. Am Rev Respir Dis 1993; 147:573-8.

8 Pollart SM, Chapman MD, Fiocco GP, et al. Epidemiology of acute asthma: IgE antibodies to common inhalant allergens as a risk factor for emergency room visits. $\mathcal{F}$ Allergy Clin Immunol 1989;83:875-82.

9 Sporik R, Holgate ST, Platts-Mills TAE, et al. Exposure to house-dust mite allergen $(\operatorname{Der} p \mathrm{I})$ and the development of asthma in childhood. A prospective study. $N$ Engl f Med 1990;323:502-7.

10 Burrows B, Martinez FD, Halonen M, et al. Association of asthma with serum IgE levels and skin-test reactivity to allergens. N Engl f Med 1989;320:271-7.

11 Sears MR, Burrows B, Flannery EM, et al. Relation between airway responsiveness and serum IgE in children with asthma and in apparently normal children. $N$ Engl f Med 1991;325:1067-71. 
12 Cookson WO, Sharp PA, Faux JA, et al. Linkage between immunolobulin E responses underlying asthma bet rhiniimmunoglobulin E responses underlying asthma

13 van Herwerden L, Harrap SB, Wong ZYH, et al. Linkage of high affinity IgE receptor gene with bronchial hyperreactivity, even in the absence of atopy. Lancet 1995;346:1262-5.

14 Postma DS, Bleecker ER, Amelung PJ, et al. Genetic susceptibility to asthma: bronchial hyperresponsiveness coinherited with a major gene for atopy. $N$ Engl $\mathcal{f} \mathrm{Med}$ 1995;333:894-900.

15 Sporik R, Chapman MD, Platts-Mills TAE. House dust mite exposure as a cause of asthma. Clin Exp Allergy 1992; 22:897-906.

16 Platts-Mills TA, Vervloet D, Thomas WR, et al. Indoor allergens and asthma: report of the Third International Workshop. 7 Allergy Clin Immunol 1997;100:S2-24.

17 Munir AK, Kjellman NI, Bjorksten B. Exposure to indoor allergens in early infancy and sensitization. $\mathcal{F}$ Allergy Clin Immunol 1997;100:177-81.

18 Arshad SH, Matthews S, Gant C, et al. Effect of allergen avoidance on development of allergic disorders in infancy. avoidance on development

19 Wahn U, Lau S, Bergmann R, et al. Indoor allergen exposure is a risk factor for sensitization during the first three years of life. F Allergy Clin Immunol 1997;99:763-9.

20 Peat JK, Tovey E, Toelle BG, et al. House dust mite allergens. A major risk factor for childhood asthma in Australia. Am f Respir Crit Care Med 1996;153:141-6.

21 Kuehr J, Frischer T, Meinert R, et al. Sensitisation to mite allergens is a risk factor for early and late onset of asthma and for persistence of asthmatic signs in children. F Allergy Clin Immunol 1995;95:655-62.

22 Marks GB, Tovey ER, Toelle BG, et al. Mite allergen (Derp 1) concentration in houses and its relation to the presence and severity of asthma in a population of Sydney schoolchildren. F Allergy Clin Immunol 1995;96:441-8.

23 Sporik R, Ingram JM, Price W, et al. Association of asthma with serum IgE and skin test reactivity to allergens among with serum IgE and skin test reactivity to allergens among children living at high altitude: tickling the drag

24 In of exposure to $\operatorname{dog}(\operatorname{Can} f 1)$ and cat $(\mathrm{Fel} \mathrm{d} 1)$ allergens: relation to sensitization and asthma among children living in Los Alamos, New Mexico. F Allergy Clin Immunol 1995 96:449-56

25 Squillace SP, Sporik RB, Rakes G, et al. Sensitization to dust mites as a dominant risk factor for asthma among adolescents living in central Virginia. Multiple regression analysis of a population-based study. Am f Respir Crit Care Med 1997;156:1760-4.
26 Salome CM, Peat JK, Britton WJ, et al. Bronchial hyperresponsiveness in two populations of Australian schoolchildren. I. Relation to respiratory symptoms and diagnosed asthma. Clin Allergy 1987;17:271-81.

27 Yan K, Salome C, Woolcock AJ. Rapid method for measurement of bronchial responsiveness. Thorax 1983;38:760-5.

28 O'Connor G, Sparrow D, Taylor D, et al. Analysis of doseresponse curves to methacholine. An approach suitable for population studies. Am Rev Respir Dis 1987;136:1412-7.

29 Peat JK, Salome CM, Berry G, et al. Relation of dose response slope to respiratory symptoms in a population of Australian schoolchildren. Am Rev Respir Dis 1991;144: 663-7.

30 Tovey ER, Chapman MD, Wells CW, et al. The distribution of dust mite allergen in the houses of patients with asthma. Am Rev Respir Dis 1981;124:630-5.

31 Luczynska C, Arruda LK, Platts-Mills TAE, et al. A two-site monoclonal antibody ELISA for quantification of the major Dermatophagoides spp. allergens $\operatorname{Der} p \mathrm{I}$ and $\operatorname{Der} f \mathrm{I} . \mathcal{F}$ Immunol Methods 1989;118:227-35.

32 Pollart SM, Smith TF, Morris EC, et al. Environmental exposure to cockroach allergens: analysis with monoclonal antibody-based enzyme immunoassays. f Allergy Clin Immunol 1991;87:505-10.

33 Munir AK, Einarsson R, Dreborg SK. Mite $(\operatorname{Der} p \mathrm{I}, \operatorname{Der} f \mathrm{I})$, cat $(F e l d \mathrm{I})$ and $\operatorname{dog}(\operatorname{Can} f \mathrm{I})$ allergens in dust from Swedish day-care centres. Clin Exp Allergy 1995;25:119-26.

34 Custovic A, Taggart SC, Woodcock A. House dust mite and cat allergen in different indoor environments. Clin Exp Allergy 1994;24:1164-8.

35 Patchett K, Lewis S, Crane J, et al. Cat allergen (Fel d 1) levels on school children's clothing and in primary school classrooms in Wellington, New Zealand. F Allergy Chin Immunol1 997;100:755-9.

36 Platts-Mills TA, Sporik RB, Wheatley LM, et al. Is there a dose-response relationship between exposure to indoor allergens and symptoms of asthma? F Allergy Clin Immunol 1995;96:435-40.

37 Mahmic A, Tovey ER, Molloy CA, et al. House dust mite exposure in infancy. Clin Exp Allergy 1998;28:1487-92.

38 Perzanowski MS, Ronmark E, Nold B, et al. Relevance of allergens from cats and dogs to asthma in the northernmost province of Sweden: schools as a major site of exposure. $\mathcal{f}$ Allergy Clin Immunol 1999;103:1018-24.

39 O’Meara TJ, De Lucca S, Sporik R, et al. Detection of inhaled cat allergen. Lancet 1998;351:1488-9. 